\title{
An Autonomous Doppler Sodar Wind Profiling System
}

\author{
Philip S. Anderson, Russell S. Ladkin, And Ian A. Renfrew \\ British Antarctic Survey, Cambridge, United Kingdom
}

(Manuscript received 19 March 2004, in final form 27 September 2004)

\begin{abstract}
An autonomous Doppler sodar wind profiling system has been designed, built, tested, and then deployed for 2 years at a remote site in Coats Land, Antarctica. The system is designed around a commercially available phased-array sodar (a Scintec flat-array sodar, FAS64) and powered from five modular power system units. Each power unit comprises two batteries, two photovoltaic solar panels, and two vertical axis wind generators, plus charging control and isolation circuitry. The sodar's main processing unit is located at the antenna, but is controlled from a manned research station $50 \mathrm{~km}$ distant, in real time, by a line-of-sight UHF radio link. Data from an integral automatic weather station (AWS) are also transmitted over the radio link, allowing meteorologically informed decisions on whether or not to operate the Doppler sodar. Over the 2-yr experiment dozens of sounding episodes, lasting from a few hours to a few days, were obtained. Successful soundings were obtained in temperatures down to $-33^{\circ} \mathrm{C}$, and wind speeds up to $12 \mathrm{~m} \mathrm{~s}^{-1}$. In general, the wind data quality was good, but the range was disappointing, probably as a result of the strongly stable atmospheric conditions that were experienced. The wind profiling system that is described has been used to obtain the first remote wintertime observations of katabatic winds over the Antarctic continent.
\end{abstract}

\section{Introduction}

Obtaining atmospheric wind profiles at remote unmanned sites is a major technological challenge, and is even more so if the site can only be attended once a year and is sited on an ice sheet. In Antarctica, this has meant that year-round in situ atmospheric profiles are rare; indeed, up until recently, they have been limited to manned research stations. Erecting masts or towers on ice is expensive and also limited, by construction considerations, to relatively low heights of typically 10$50 \mathrm{~m}$. Automatically launched radiosonde balloon ascents are available [e.g., the Vaisala Automatic Upper Air Sounding System (AUTOSONDE) can launch up to 24 balloons before requiring refilling], but these only provide one profile per balloon ascent, and their complexity of operation constrains their suitability to sites with relatively frequent access for maintenance and nonhostile environments. Wind profilers that are based on Doppler radar techniques do not have the resolution

Corresponding author address: Dr. P. S. Anderson, Physical Sciences Division, British Antarctic Survey, Natural Environment Research Council, High Cross, Madingley Road, Cambridge, CB3 OET, United Kingdom.

E-mail: philip.s.anderson@bas.ac.uk that is required for boundary layer studies and, furthermore, do not perform well in regions of low humidity.

Antarctica offers many difficult technical problems for autonomous engineering; for example, the low temperatures and high wind speeds of the continent are well known (e.g., King and Turner 1997). However, equipment failure is as often caused by blowing snow, electrostatic discharge in blizzards, or the various effects of hoar or rime ice accumulation. Rime ice occurs through the freezing of supercooled water droplets and so is more common close to the coast where fog or low-level clouds form. Rime in Antarctica is usually of a low density, amorphous, and delicate. In a thick fog it can accrete rapidly and build up to a $10-\mathrm{cm}$ depth in lattice or hollow structures. Hoar frost occurs from the freezing of water directly from the vapor phase and is the result of (radiative) cooling of a structure to below the local frost-point temperature. Hoar is thin, crystalline, and accretes slowly, but is difficult to remove from any material (see Glickman 2000).

The above environmental constraints, the high cost of logistical support, and the difficulty of access to remote sites combine to produce a stringent set of design criteria for any autonomous system. In this paper, we use "remote" to mean an unmanned site with limited year-round access, and "station" to be a research facil- 
ity where personnel are available to maintain equipment or effect repairs when necessary. Remote equipment must have a long mean time between failure, preferably more than $5 \mathrm{yr}$, to ensure confidence in recording data for a full unattended year. Hence, a philosophy of keeping the design as simple as possible, with a minimum of moving parts, and by using isolated modular units, has proven successful. In addition, in our experience, electrostatic discharge protection, shielding, and overengineering of the system mechanics enhances the survival rate of electronics-based systems.

Remote systems based upon Doppler sodar techniques offer the possibility of continuous wind profiling and fit the above design criteria. Their disadvantage is that they are relatively power hungry compared to more passive systems, such as automatic weather stations.

Sodars of various types have been used in the polar regions for decades, but always at either occupied stations with mains power or during summer, and usually both. Neff (1978) and Hall and Owens (1975) report on echo-strength profiles recorded by a sodar at the Amundsen-Scott Station, South Pole. This appears to be the first use of sodar in the polar regions, with the instrument recording echo-strength profiles to indicate the depth of the boundary layer and turbulent structure. Neff (1978) describes a mono-/bistatic system of two antennas used at Amundsen-Scott in 1977, which was partially Doppler (along the monostatic beam), and was operated during summer. Since that time, the Environmental Technology Laboratory (formerly the Wave Propagation Laboratory) has run a variety of Doppler sodars year-round at the South Pole; a review of these studies is presented in Neff (1996). Sodars started operating at the Antarctic coastal sites during the 1980s in various configurations, such as singleantenna backscatter profilers at Halley (King et al. 1987; Rees and Mobbs 1988), and single-axis and triaxis Doppler systems at Terra Nova Bay (Mastrantonio et al. 1988, 1990; Fiocco et al. 1990; Argentini and Mastrantonio 1994), but, always at a research station, and, therefore, with mains electric power. Remote sodar operations at field sites have occasionally been made during the summer, for example, on the Siple Coast (e.g., Bromwich and Liu 1996).

Invariably, the above studies have used the traditional parabolic dish and acoustic enclosure design. The tendency for the bucket-shaped enclosure to accumulate snow during blizzard conditions appears to depend on subtleties in the enclosure design; the system known to the authors at Halley-a single Sensitron vertically pointing antenna-suffers surprisingly little from such problems, whereas similar radio acoustic sounding sys- tem (RASS) shielding that is used at Amundsen-Scott Station requires a near-continual manual removal of snow (W. D. Neff 1996, personal communication). Small dustings of snow on the antenna dish may well degrade the antenna gain through sound absorption, but it is readily evaporated by modest heating of the dish. At a remote site, and especially a remote site in winter, even modest heating is beyond the present power capabilities. For this reason, the dish and bucketstyle antenna was deemed unsuitable for our project.

Doppler sodar systems work by transmitting acoustic pulses upward into the atmosphere and detecting the Doppler shift in the backscatter signal. By using offvertical acoustic paths it is possible to calculate the velocity profile of the reflector, which is then assumed to be identical to the wind profile (Neff and Coulter 1986). Acoustic backscattering occurs in volumes of the inhomogeneous acoustic refractive index, which is dominated by temperature variability on scales similar to that of the acoustic wavelength. Under stable atmospheric conditions, such variability is the result of shear-induced turbulence acting on a mean temperature gradient. (Panofsky and Dutton 1984; Tatarskii 1971). The autonomous Doppler sodar system described here was built around a modified commercially available system and was powered by batteries that were charged from photovoltaic panels and wind generators. The sodar's main processing unit was at the remote site, but was controlled through a standard personal computer (PC) located at a nearby manned research station (Halley). Communication between the remote sodar system and the control computer at the station was via a line-of-site UHF radio link. Meteorological data from an automatic weather station (AWS) at the remote site were also telemetered via the radio link so that decisions on sounding could be guided by meteorological conditions at the remote site as well as meteorological observations at the station, satellite images, and synoptic forecasts.

In the next section further details of the system design are described. Section 3 details the experimental setup of the system during a 2-yr experiment in Coats Land, Antarctica. Section 4 provides some illustrative wind profiles from Coats Land and compares them against in situ wind profiles from a kite-borne tethersonde. Sections 5 and 6 discuss the performance of the power system and wind profiler during the 2-yr Coats Land experiment, while section 7 concludes the paper.

We should stress that scientific results from the profiler and presentation of the wintertime data will be presented elsewhere, for example, Renfrew (2004) and other papers in preparation; this paper concentrates predominantly on the performance of the system. 


\section{System design}

The main elements of the system are the Doppler sodar sounding antenna and processing unit, and the power system, control unit, and telemetry equipment (Figs. 1 and 2).

\section{a. Doppler sodar Antenna}

The autonomous Doppler sodar system was built around Scintec's flat-array sodar FAS64, which uses an $8 \times 8$ phased array of piezoelectric transceivers to steer the acoustic pulses electronically in different directions. The FAS64 design uses a split-beam technique, where the phases of the antenna are such that the two beams are transmitted simultaneously in opposite directions, but with differing off-vertical angles of $29^{\circ}$ and $22^{\circ}$. Analysis of the returning Doppler signal assumes a level of horizontal homogeneity in the wind profile; the two returning signals (from different directions and different off-vertical angles) will then have a Doppler difference, which gives the wind velocity. The beam pair is steered into four quadrants during a profiling cycle, effectively giving four samples of $u$ and four samples of $v$ per cycle. This split-beam technique was used throughout our site tests and field work.

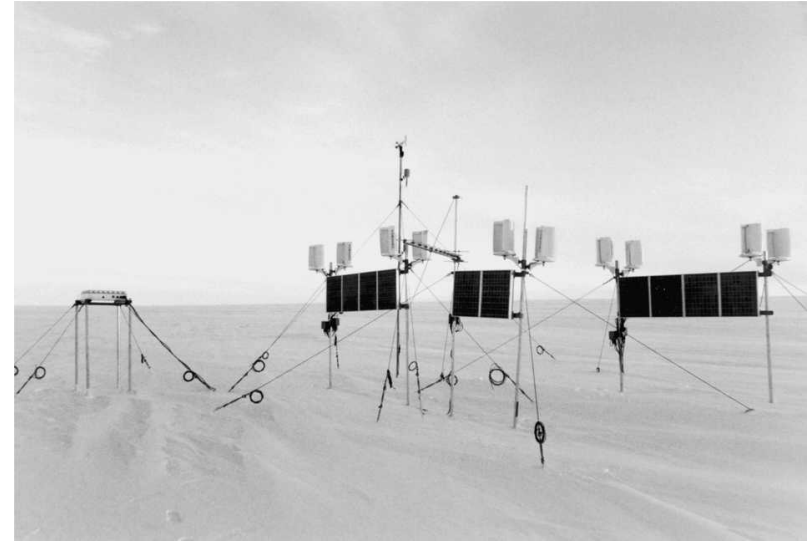

FIG. 2. Photograph of the Doppler sodar wind profiling system after installation in 2001/02. The photo is looking toward the southwest. In the foreground is the sodar antenna; to the right are the three rows of solar panels, the wind generators, and the radio antenna. To the left is the mast of the AWS.

The FAS64 uses a set of pulses of different frequencies, transmitted sequentially, to improve the vertical range and resolution. Higher acoustic frequencies are attenuated more rapidly in air, but the shorterwavelength scale allows for a finer resolution when operating in a Doppler mode. Low frequencies are attenu-

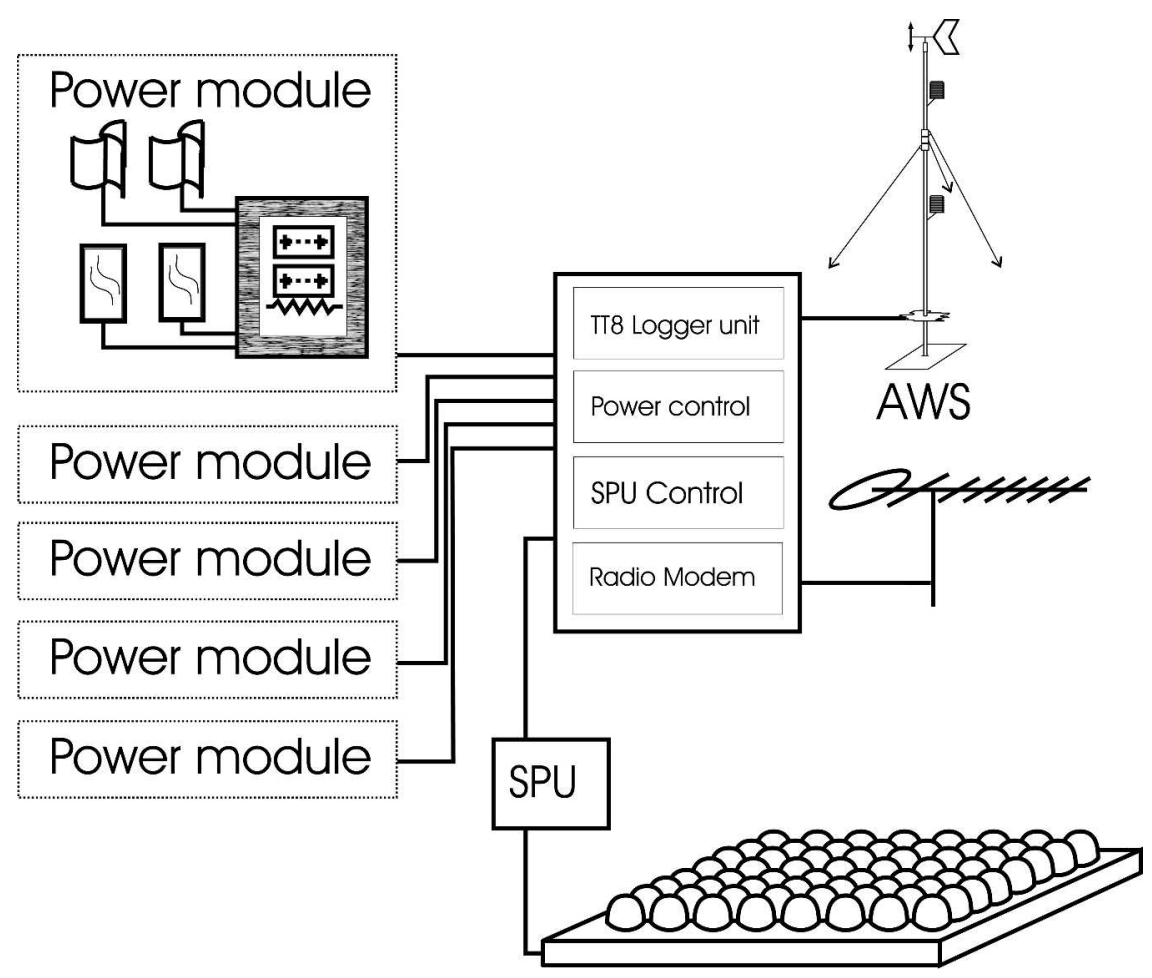

FIG. 1. Schematic of the autonomous Doppler sodar system in Coats Land. Each power module comprises two wind generators, two solar panels, two batteries with heaters, and regulation circuits. 
TABLE 1. Pulse frequencies, durations, and the minimum height at which a pulse can contribute for the two settings used in the Coats Land experiment: 502 (high resolution) and 506 (standard resolution). The pulse durations are given as an equivalent distance (rather than time) as set in the sodar-controlling software. The final column is the time before the Doppler sodar can start listening, i.e., the total transmitting time plus a pause (equivalent to $20 \mathrm{~m}$ ). Note that 10 different frequencies were always used.

\begin{tabular}{|c|c|c|c|c|c|c|c|c|c|c|c|}
\hline & \multirow[b]{2}{*}{ Setting } & \multicolumn{10}{|c|}{ Pulses } \\
\hline & & 1 & 2 & 3 & 4 & 5 & 6 & 7 & 8 & 9 & 10 \\
\hline Frequency $(\mathrm{Hz})$ & 502 and 506 & 2004 & 2073 & 2141 & 2227 & 2313 & 2399 & 2484 & 2570 & 2656 & 2741 \\
\hline Pulse durations $(\mathrm{m})$ & & 50 & 50 & 40 & 40 & 30 & 30 & 20 & 20 & 10 & 10 \\
\hline Minimum height that a pulse can contribute (m) & 502 & 320 & 270 & 220 & 180 & 140 & 110 & 80 & 60 & 40 & 30 \\
\hline Pulse durations $(\mathrm{m})$ & & 60 & 60 & 50 & 50 & 40 & 40 & 30 & 30 & 20 & 20 \\
\hline Minimum height that a pulse can contribute (m) & 506 & 420 & 360 & 300 & 250 & 200 & 160 & 120 & 90 & 60 & 40 \\
\hline
\end{tabular}

ated less, but require longer pulses to achieve the same Doppler resolution. Although the FAS64 pulse set design is flexible and can be changed by the user, the recommended style consists of initially long, low frequencies with subsequent shorter, higher frequencies. During transmission, the antenna cannot receive any return-echo signal, and so the first pulse of the set is effectively ignored until the whole pulse set has been transmitted. The last pulse of the set is used for nearsurface profiling and should, therefore, be the shortest, highest frequency. Conversely, the first pulse, which may only contribute profiling information some 100$200 \mathrm{~m}$ or more above the surface, should be of a lower frequency.

The frequency set and range gate characteristics could all be changed to suit the operational environment. This was necessary because acoustic backscatter strength varies considerably according to atmospheric stability and the level of turbulence, and with a system operating in a novel environment, the optimum characteristics were not known a priori. With a limited time in which to search for an optimum configuration, only a few pulse settings were tested, with advice taken from the manufacturers. The two most promising settings, designated 502 and 506 (see Tables 1 and 2 for details), were then used during the Coats Land experiment.

\section{b. The power system}

The British Antarctic Survey (BAS) has developed a $12-\mathrm{V}$, modular power system for use in polar autonomous observatories, where the average continuous power requirement is less than $10 \mathrm{~W}$. Each module consists of two 12-V, 100-A-h lead-acid gel batteries (Exide SUNLyte 12-5000X), a 40-W photovoltaic solar panel (Kyocera KC40), and an optional vertical axis wind generator (Forgen 500 or 1000). A temperaturedependant regulator circuit is used to provide the optimal charging voltage to the batteries. The batteries themselves are contained in an insulated enclosure with the regulator so that waste heat from the regulation is used to heat the batteries and increase their capacity. There is also an external load to dump power if the batteries exceed $30^{\circ} \mathrm{C}$. Modules are cascaded together for increased power requirements.

During active sounding, the operating power that is required by the Doppler sodar antenna and processing unit was measured with a $70-\mathrm{W}$ mean and $100-\mathrm{W}$ peak from a dual $\pm 12 \mathrm{~V}$ supply. It was realized at an early stage in the design that we could not guarantee sufficient wintertime power for continuous operation and that a $24-\mathrm{V}$ power system would be required for direct current (DC)-DC converters to provide sufficient power. Therefore, our standard $12-\mathrm{V}$ modules were modified for $24-\mathrm{V}$ operation, with each module taking power from two solar panels and two wind generators (Forgen 1000). Five of these modules were constructed to increase the power capacity, with each isolated to provide resilience to the failure of individual modules and combined into the central control unit.

BAS has over a decade of experience using wind generators as a source of wintertime power, when the months of darkness preclude using photovoltaics, and, over this time, the following number of points of failure have been noted:

- bearing failure resulting from continuous rotation (The surface wind regime may be so persistent that the expected number of rotations before failure is exceeded in less than 12 months.);

- bearing failure resulting from ice particle ingress (At low temperatures, blowing snow becomes a fine abrasive "dust" that can enter the bearings area and add to wear.);

- jamming of any active feathering mechanisms by ice, leading to overrevving and hence destruction.

Given these problems, a vertical, noncommutator self-limiting wind generator was used, the Forgen 1000. Unlike the more familiar propeller turbines, these units become ever more inefficient at high wind speeds and, therefore, do not require active feathering to restrain 
their upper rotational speed. They have only one set of bearings and no commutator thus reducing the complexity of design. The only inherent design drawback is a poor overall efficiency, but for our application this was easily compensated for by adding more generators. The logistical costs and, therefore, the importance of nonfailure, once deployed, easily outweighs the additional costs of extra generators.

\section{c. Logging and control unit}

A BAS-designed logger unit, based around the Onset TT8 micrologger, controls the sodar processing unit (SPU), AWS, telemetry, and power switching. The logger waits in a quiescent mode, waking once an hour to take AWS measurements and record housekeeping data, such as battery levels, charging voltages, and internal temperatures. These data are archived to a flash memory card within the logger and then are telemetered to a PC at a manned station. Once these data have been sent, the telemetry system remains active for $1 \mathrm{~min}$ to listen for commands from the station before returning to a quiescent mode. This 1-min listening period is reset if characters are being received, up to a maximum of $5 \mathrm{~min}$, when the system returns to the quiescent mode if a sounding has not been commenced.

The station personnel can send commands to the remote site when the logger is awake and thereby reset the clock, changing the time between wake periods, remeasuring housekeeping data, and starting or stopping a sounding.

Although the principle of operating the Doppler sodar remotely by extending the PC to the signal processing unit (SPU) communication link by a radio link was simple; in reality, subtle problems were encountered. The SPU unit is controlled by a small onboard computer system running its own software. The Scintec FAS64 system allows for continual upgrading of the SPU software by downloading an operating program from the PC whenever the SPU is switched on. Under normal conditions, with the PC linked to the SPU by a robust serial line, this is the simplest solution to maintaining software compatibility if the PC software is upgraded. When extending the communication link with the radio modem, the lack of an in-built PC to the SPU error-free transfer protocol and the slower speed of the radio link meant that such downloads failed. The solution was to keep copies of the SPU programs on the Tattletale 8 (TT8) logger system at the remote site. However, this did not allow for any upgrade of the SPU program files except during annual site visits. We mention this aspect of the software not as a criticism of the Scintec design, because the unit was never intended for 
remote operation, but, rather, because we believe that in the future, the autonomous operation of instruments will become increasingly common, and the research community will benefit from equipment that can operate over slow, sporadic, and asynchronous communication routes, which are more akin to the Internet than to a serial port.

Sounding is initiated by the station personnel during the (hourly) wake period of the remote logger. The logger unit powers up the SPU and antenna, allows the SPU to boot, and then downloads the SPU program file directly. At this stage the system telemeters a report back to the station PC on the success or failure of this operation. Success indicates that the station operator can now start the normal Scintec FASRUN sounding software on the station PC. The logger controls the flow of the data over the telemetry link between the FASRUN software (at the station) and the SPU (at the remote site). During sounding operations, the logger also eavesdrops on the communication stream, and hence interprets the status and termination commands from the user. The logger includes a watchdog to detect for the unexpected stopping of the data flow, in which case the system returns to its quiescent state to conserve power.

\section{d. Telemetry}

The telemetry system uses two programmable transceiver units [Wood and Douglas RSX450 with Gaussian Minimum Shift Keying (GMSK) modems] using two separate frequency channels. Data transmission to the modems is at 19200 baud, but the over-air data rate is only 9600 baud. Hardware handshaking is used to control data flow to the modems. The station transmitter, where power is not a consideration, is programmed for $500 \mathrm{~mW}$, while the remote unit operates at $100 \mathrm{~mW}$. Both units were connected to horizontally polarized, 10-element yagi antennas.

\section{The Coats Land experiment}

The Doppler sodar system was designed to achieve the scientific objectives of obtaining year-round wind profiles on the slopes of Coats Land. This region is prone to persistent katabatic winds. On a larger scale, such drainage flow is important throughout Antarctica because of its influence on local weather conditions and its contribution to the general circulation of the Southern Hemisphere (King and Turner 1997; Renfrew and Anderson 2002).

Coats Land has been the focus of a study of katabatic winds for several years (King 1993; Renfrew and
Anderson 2002; Renfrew 2004; Ye et al. 2005), being immediately south of the Brunt Ice Shelf, the location of BAS's Halley research station at $75.60^{\circ} \mathrm{S}, 26.20^{\circ} \mathrm{W}$. The autonomous Doppler sodar system was installed in February 2002 at $75.96^{\circ} \mathrm{S}, 25.41^{\circ} \mathrm{W}, 400 \mathrm{~m}$ above sea level, and $45.5 \mathrm{~km}$ south of Halley. This site had hosted an AWS for the previous $6 \mathrm{yr}$ and was part of a suite of AWS sites in Coats Land. A climatological study of the surface meteorology of Coats Land is described in Renfrew and Anderson (2002). The Doppler sodar, without the autonomous power system, was first tested in January and February 2000 at Halley Station on the Brunt Ice Shelf. The power system was tested during the austral winter of 2001 adjacent to Halley.

Figure 1 sketches the layout of the Doppler sodar system, as installed in Coats Land. The five power unit boxes were buried to reduce heat loss to the atmosphere and provide protection from the lowest surface air temperatures. The battery storage capacity is a function of temperature, and this simple procedure improves the wintertime performance of the gel cells. The main control box, containing the logger, power control circuitry, and pressure sensor was also buried, in this case, to reduce blizzard-induced electrostatic discharge effects, and improve the quality of the pressure readings (see Anderson et al. 1992). The five solar panel pairs were mounted vertically and faced north, in order to receive the maximum possible direct sunlight during the days following winter when the battery capacity would be at its lowest. A vertical aspect is used because it best encourages the shedding of any snow accumulation on the panel surfaces. The UHF yagi radio antenna pointed north-northwest toward the receiver at Halley. The sodar antenna was placed on the (climatologically) upwind side of the solar panels and wind generators. It was mounted approximately $2 \mathrm{~m}$ off the ground, above the height of the solar panels, to avoid echoes from the panels. Figures 2 and 3 are photographs from the experiment site. The integrated AWS is located a few meters to the south of the Doppler sodar, with a 4-m tubular instrument mast. Two other totally separate AWSs were also operating at this site.

As discussed in section 2, the autonomous power system did not provide sufficient power for continuous profiling. Instead, our approach was to monitor conditions at the remote site and make an informed decision about whether to commence sounding. A series of sounding criteria were drawn up to enable the overwintering Halley-based personnel to make a decision on whether to initiate a sounding and to judge for how long the sounding should last. The criteria were essentially as follows. 


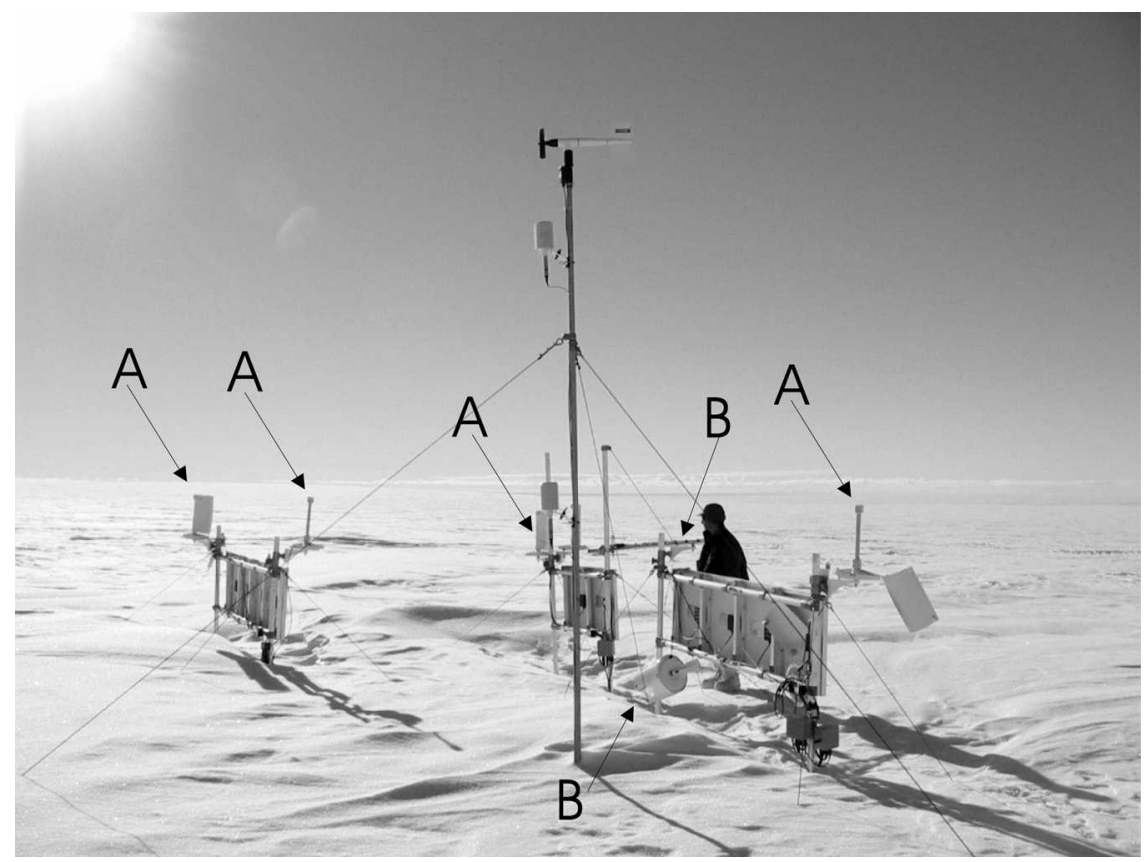

FIG. 3. Photograph of the Doppler sodar wind profiling system after $1 \mathrm{yr}$ of remote operation. The photo is looking toward the southeast. Three types of damage to the wind generator impellers is evident: "A": where some, or all, of the impeller blades are missing; "B": where the mounting bracket has been sheared, and not shown; "C": four generators completely missing, later found buried.

1) Is there adequate power? Examining the battery input voltage gave an indication of the capacity of the power system; theoretical calculations and experience suggested that periods of $12-48 \mathrm{~h}$ of use should be possible for reasonably well charged batteries. The battery voltage was monitored during the course of any sounding period, and the sounding terminated when the dual-battery levels fell below $22 \mathrm{~V}$.

2) Are the meteorological conditions interesting? Surface meteorological conditions at both the Halley and Coats Land sites could be checked for suitability for study. In particular, we developed a series of scenarios based on the time of year and real-time observations of cloud cover, wind speed, and wind direction for situations of meteorological interest. The scenarios were of the (a) wintertime katabatic flow, (b) autumn/spring katabatic flow, (c) calm to katabatic flow transition, and (d) synoptic-scale low pressure-system to katabatic flow transition. Our aim was to obtain several case studies from each type of scenario.

A period of $12-48 \mathrm{~h}$ was usual for any one sounding period, although a couple of episodes covering several days were obtained.
As discussed earlier, a set of sounding parameters had been predefined and undergone limited testing prior to deployment. These had different vertical resolutions (range gates), pulse frequencies, and pulse durations, with the aim to optimize the resolution, range, and data quality. However, because of the changing state of the atmosphere (and hence the changing strength of the acoustic backscatter), it was quite difficult to objectively test the relative merits of the different settings. During deployment in Coats Land, the two most promising settings were chosen, referred to as 502 and 506 (see Tables 1 and 2). The range coverage that is achieved for these two settings is compared in Fig. 4. The two settings used the same number of pulses and the same frequency for each pulse, with the key difference being that 506 used slightly longer pulses than $502-20 \%$ longer at lower frequencies, and $50 \%$ at higher frequencies. Hence, 506 should have had a better range to the detriment of resolution.

Figure 4 shows that the percentage of good quality wind observations as a function of range gate for each setting as marked. The data plotted are from 2629 sounding profiles from over 50 separate days; of these $43 \%$ were setting 502 and $57 \%$ were setting 506 . The data are binned by range gate, with the height label indicating the midpoint of the range gate. Interestingly, 

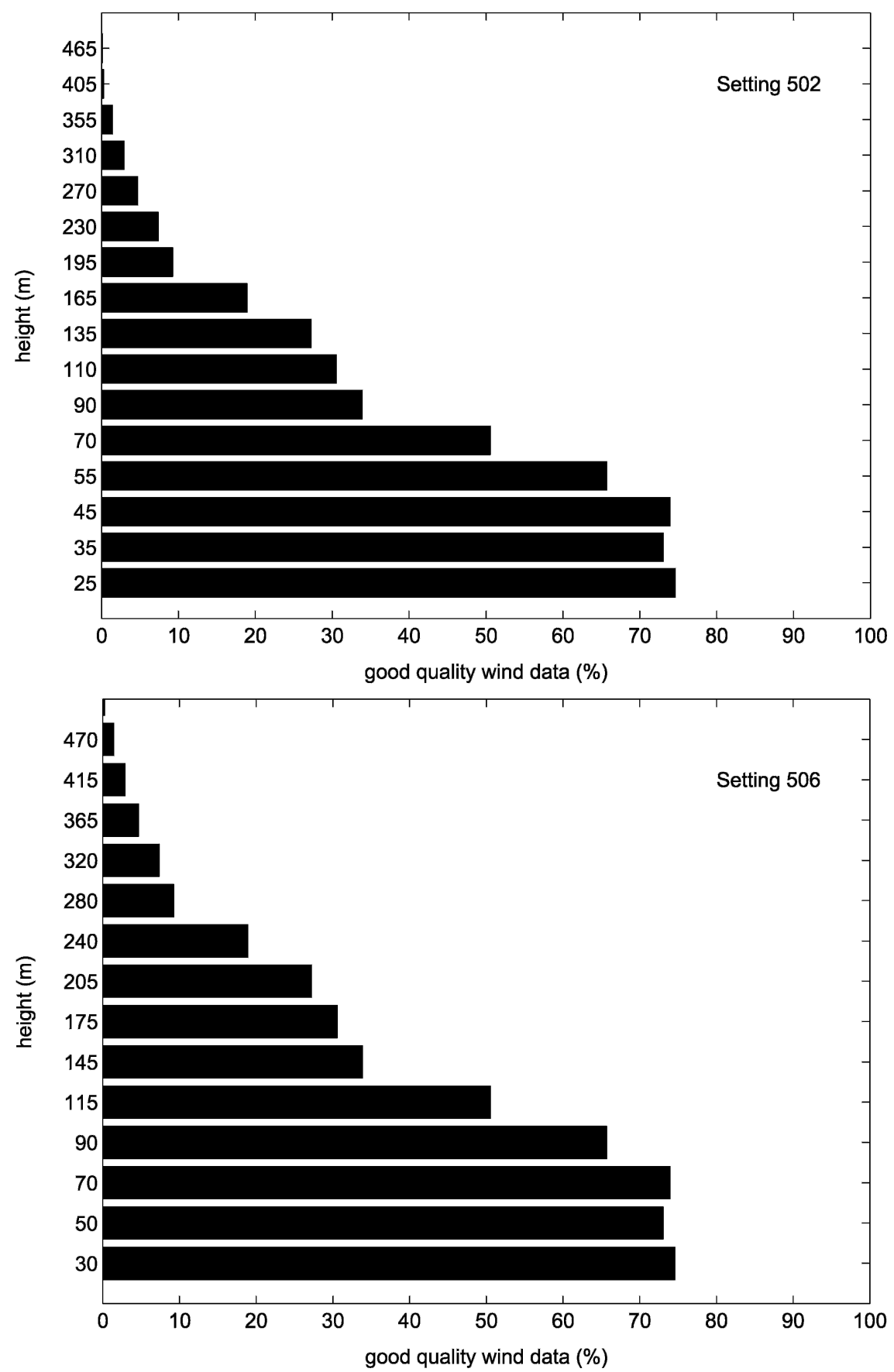

FIG. 4. Histograms showing the percentage of good quality wind observations as a function of range gate for the two sodar settings 502 and 506, as marked. The observations are binned by range gate, and the height of the midpoint of each range gate is labeled. The similar decrease in quality with range gate means the 502 setting has a better resolution, but a worse range than the 506 setting.

the decrease in quality with range gate is remarkably similar for both settings. For example, the lowest three range gates have $\sim 75 \%$ coverage, the fourth has $\sim 65 \%$, the fifth $\sim 50 \%$, and so on, for both settings.
Because of the different vertical resolutions, this effectively means that setting 502 gave a higher resolution but a lower range, and setting 506 gave a lower resolution but a longer range. Although $75 \%$ good quality 

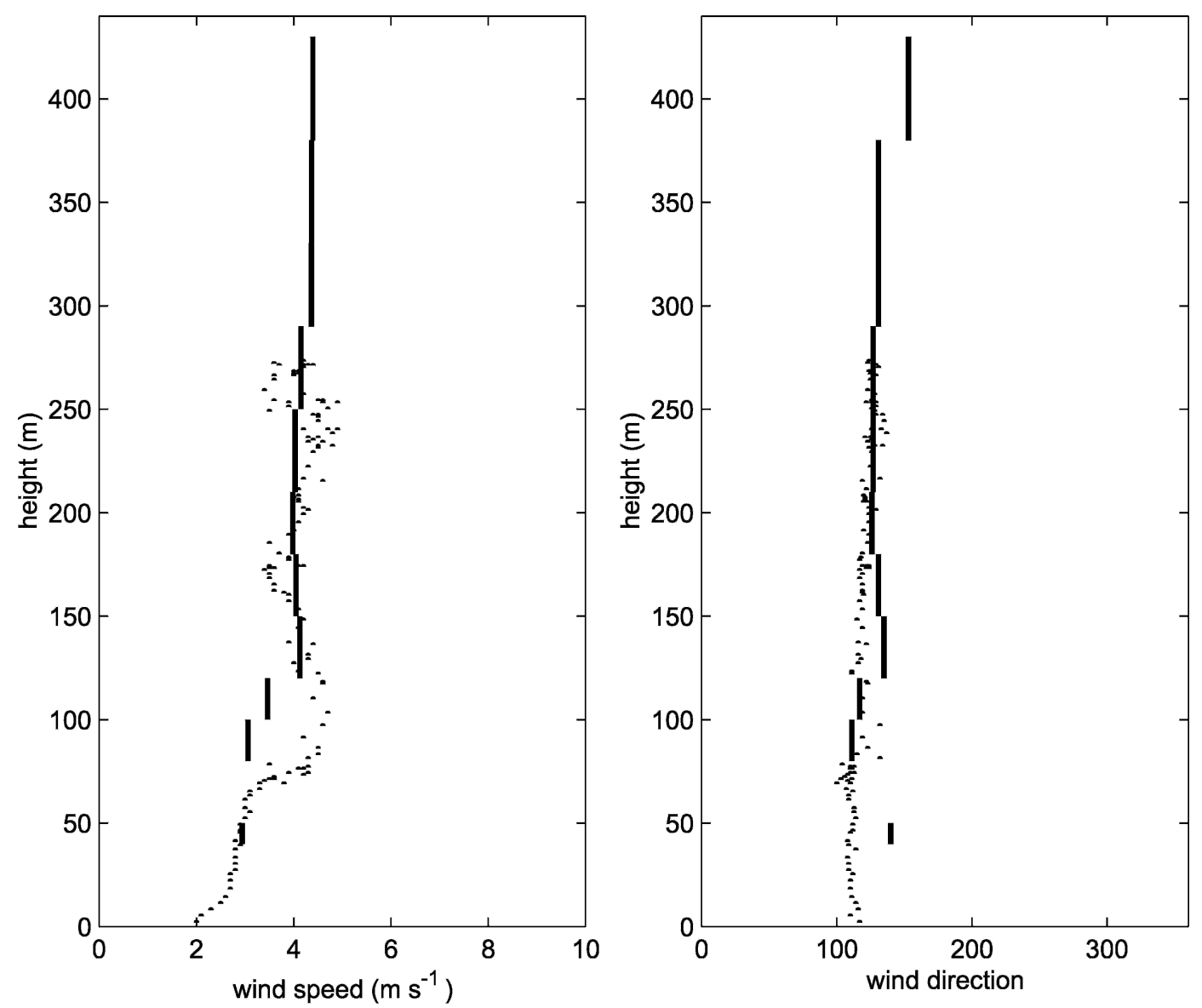

FIG. 5. Wind profiles from the Doppler sodar (vertical bars) and a tethersonde system (dots) on 14 Feb 2000. The Doppler sodar was situated $5 \mathrm{~km}$ to the west of Halley, on the Brunt Ice Shelf, while the tethersonde system was at Halley. The Doppler sodar wind profile is a 15-min average ending at 2030 UTC, while the tethersonde profile is from 2018 to 2041 UTC.

data may not appear to be that successful, it should be stressed that periods of good quality and bad quality data were clustered in time. There tended to be several hours of near-perfect sounding on some days, while on others the data quality was sporadic resulting from a variety of problems, such as low power, high wind speeds generating environmental noise, and so on. The difference between the two settings implies that to achieve an improved range would require a further extension of the lower-frequency pulse lengths. The good data coverage near the surface for both sets also indicates that the shorter pulse lengths of setting 502 may be retained, which would maintain the highest possible vertical resolution.

\section{Profile test results}

Figures 5 though 8 show two comparisons between Doppler sodar and tethersonde wind profiles. Figure 5 shows a comparison of cotemporal Doppler sodar winds and tethersonde winds from 14 February 2000. Figure 6 shows a time series of all available Doppler sodar wind profile data for that day. The profiles were taken during the summertime testing of the Doppler sodar $5 \mathrm{~km}$ west of Halley on the Brunt Ice Shelf. The Doppler sodar winds are a 15-min average ending at 2030 UTC, while the tethersonde winds are from a profile between 2018 and 2041 UTC flown at Halley. A helium-filled kite (Helikite) was used to fly the tethersonde in this case. Qualitatively speaking, the wind profiles compare well. The main feature in both profiles is the step in wind speed with height, from about 3 to $4-5$ $\mathrm{m} \mathrm{s}^{-1}$, that occurs around $70-100 \mathrm{~m}$ above the surface. The step is a little higher in the Doppler sodar winds; the difference is possibly caused by the instruments not being exactly collocated, and by the effects of the inherent averaging of the sodar. Both wind direction profiles are essentially constant with height at around $100^{\circ}-120^{\circ}$.

Figure 7 shows Doppler sodar winds and tethersonde 


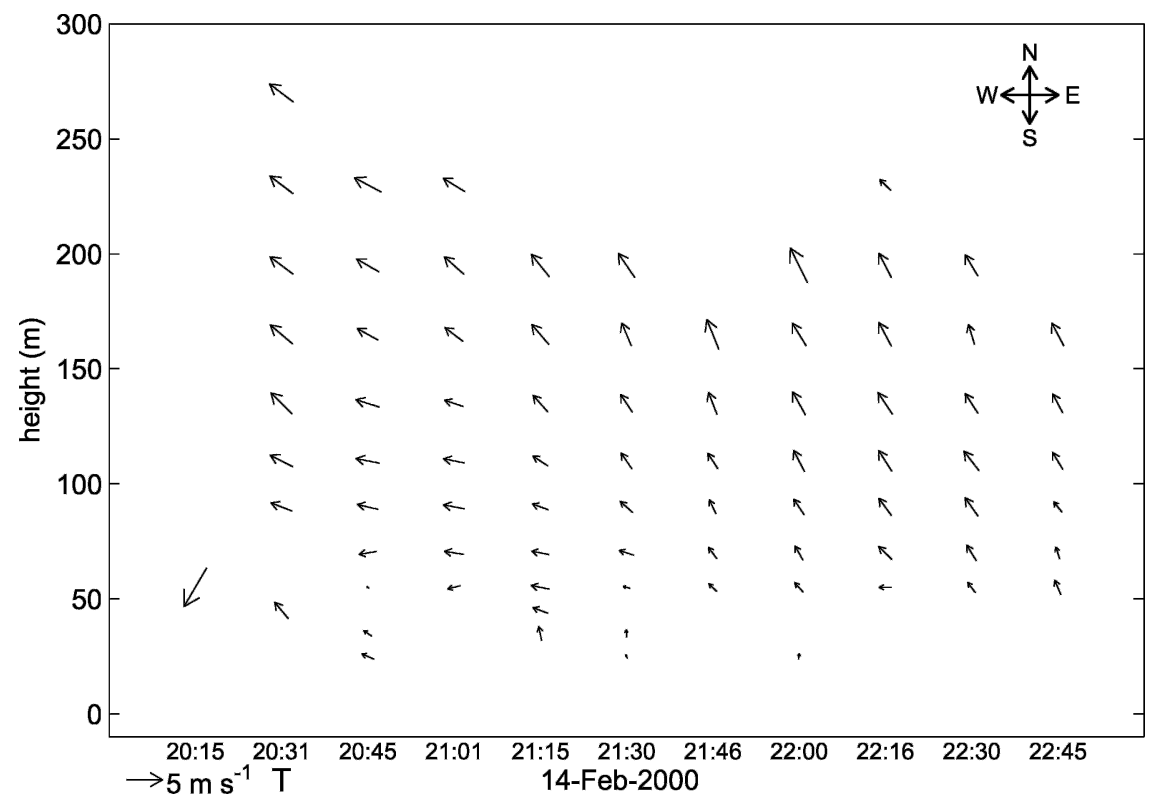

FIG. 6. Time-height vector plot of sodar horizontal wind profiles for 14 Feb 2000. The data coverage shows few missing levels, and magnitudes of both $\partial s /\left.\partial z\right|_{t}$ and $\partial s /\left.\partial t\right|_{z}$ are moderate and locally monotonic, where $s$ is the magnitude of the wind vector; the data appear realistic.

winds from 7 February 2002, with the corresponding time-height plot for the full sodar data in Fig. 8. In this case, the profiles were taken at the Coats Land site at the time of the installation of Doppler sodar system. Unfortunately, logistical constraints during the 2001/02 Antarctic field season-restricted system testing to a very limited number of comparison profiles. The Doppler sodar winds are a 15-min average ending at 1915 UTC; the tethersonde winds are from a profile between 1914 and 1928 UTC. The tethersonde was flown beneath a kite and a horizontal kite velocity of $0.43 \mathrm{~m} \mathrm{~s}^{-1}$ (estimated using a line angle of $30^{\circ}$ ) has been subtracted from the tethersonde winds to account for the horizontal drift of the kite platform during winch operations.

The FAS64 flags each wind observation with a quality control index, which provides the user with a level of confidence in the data. The index flags low-level warnings, for example, "large difference between original data and Gaussian fit"; to medium-level errors, for example, "Unable to locate the center (sic) of the spectral peak within the selected wind range"; to fatal errors, for example, "A very strong fixed echo was detected." Fatal errors produced no wind profile data at all, but low to medium errors still generated data. We combined all data with null or warning-only errors to be those of a good quality, and all other data, that is, with mediumlevel errors, as those of a poor quality. All available Doppler sodar profile data are shown in Fig. 7.
There is a marked difference between the sodar and the tethersonde data in the near-surface winds. Inspection of the time series Fig. 8 indicates that, for this occasion, the sodar data are not realistic: unlike the series shown in Fig. 6, the sodar profile data around the time of the comparative tethersonde flight is fragmented, and sequential profiles show large differences in the wind vectors and profile coverage. The large number of high-error values in the profiles before and after 1915 UTC, combined with the qualitative inconsistency of the time series, suggests that, in this case, the Doppler sodar wind profiles may be in error, despite the low-error numbers at 1915 UTC. Such plots are not atypical of the data recovered from the sodar system during the winter. Hence, in our quality control procedure, we use both the associated error reports and check the time series, before accepting the observations.

\section{Power system performance}

The power system that is used with the Doppler sodar achieved partial success over the experimental period. However, it did not provide the designed power output over the duration of the experiment, primarily because of the failure of the wind generators. That notwithstanding, the system was sufficiently robust that failure was gradual, rather than catastrophic, and sounding was able to proceed throughout the $2 \mathrm{yr}$, al- 

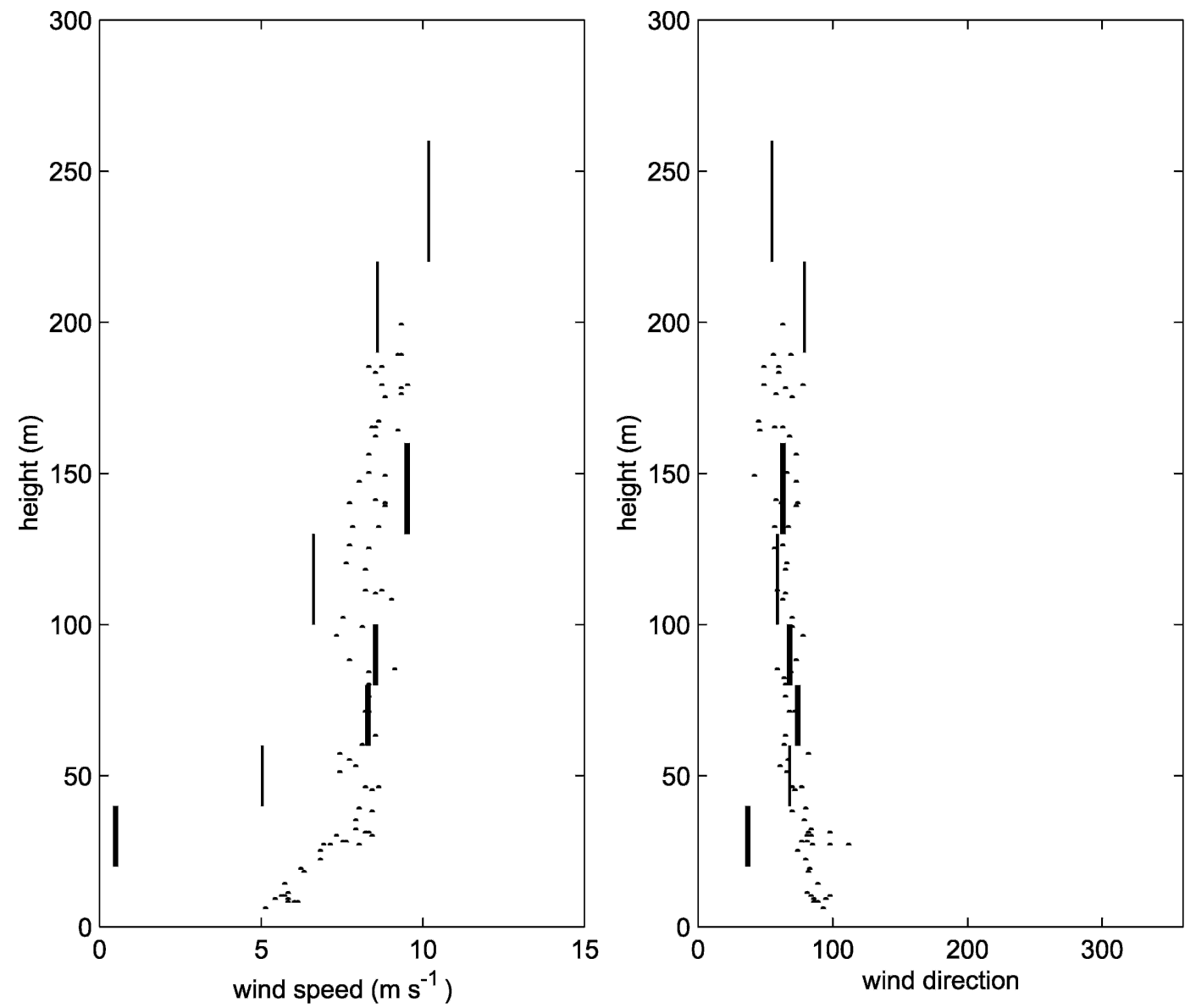

FIG. 7. Wind profiles from the Doppler sodar (vertical bars) and a tethersonde system (dots) on 7 Feb 2002 at the remote site in Coats Land. The Doppler sodar wind profile is a 15-min average ending at 1915 UTC, while the tethersonde profile is from 1914 to 1928 UTC. Both high-quality sodar winds ( $e<128$; thick bars) and low-quality sodar winds $(e<300$; thin bars $)$ are shown.

beit on a more limited schedule than was planned. This section is included to give an idea of the difficulties in running moderate-powered autonomous systems in the polar regions; in no way should it be taken to imply a criticism of the components that were used in the power units.

The main cause of the reduced power was the inability of the wind generators to survive for extended periods (more than about a month) when confronted with excessive asymmetric loading, caused by rime/hoar deposits on the rotor blades. This had been observed during the power-system tests during the winter of 2001 at Halley, where some damage occurred to the rotors and generator mountings during high winds that were associated with a major weather system. Figure 9 shows one of the wind generators with rime accumulation as observed in 2001. Eight of the 10 wind generators were damaged during this test period, 7 of which were repaired and 1 that was replaced. In all cases, damage appeared to be initiated by a vibration-induced loosening of key components on either the generator or the mounting bracket. The loosening of nuts and bolts (or screws) by vibration is well known in climates that have large and rapid temperature changes. In addition, at low temperatures standard friction nuts tend to become loose because the plastic inserts becomes less resilient. Before deployment in Coats Land in February 2002, the wind generators were rebuilt using locking compound on all threading.

After $1 \mathrm{yr}$ of remote operation, significant damage had again occurred to the blades, mounting bolts, and spindles. We stress that these wind generators were not modified or strengthened in any way and were, therefore, not designed to withstand continual vibration and asymmetric loading. Mounting and spindle shear was always accompanied by blade damage, indicating that as the blades warped or came loose, the additional vibration on top of the ice loading induced the failure of 


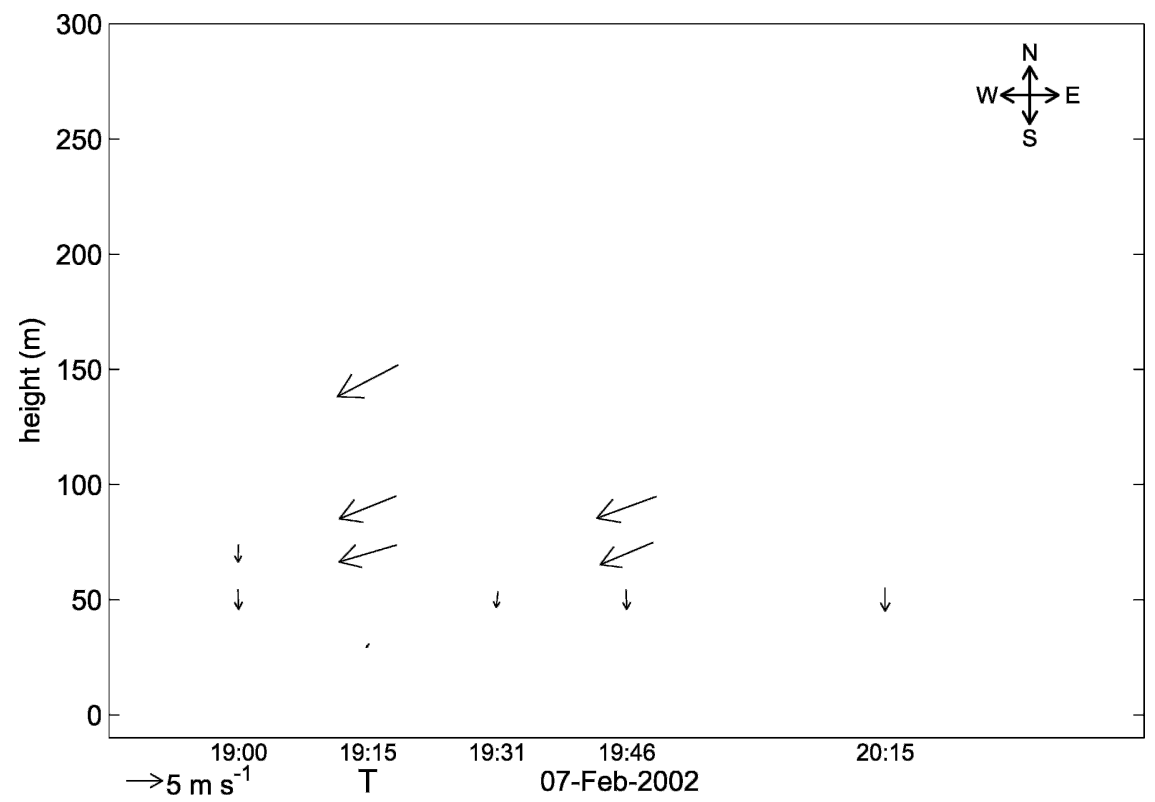

FIG. 8. Time-height vector plot of sodar wind profiles for the same day as Fig. 4. Data are missing from within individual profiles, and both $\partial s /\left.\partial z\right|_{t}$ and $\partial s /\left.\partial t\right|_{z}$ have significant discontinuities. Internal data quality checks by the sodar system indicate that the profiles are of a "high quality," but inspection of the vector plot indicates that the profiles are suspect. Both system quality and inspection are required to provide acceptance criteria.

the more robust components, such as the mounting brackets; had the blades not suffered any initial damage, the cascade of failure may not have occurred. Both Halley and the remote site on Coats Land are relatively close to the coast and so are prone to rime and hoar frost buildup. It is possible that farther inland, this effect is less severe and ice loading will be much reduced.

Despite the destruction and, in some cases, electric shorting of the wind generator units, the power system had an inherent isolation to prevent partial failure from affecting the rest of the system. Hence, the photovoltaic panel units and control circuits still functioned as planned throughout the experiment.

\section{Wind profiler performance}

During 2002 and 2003 approximately 30 sounding periods were obtained, ranging from a few hours to a few days. About half of these are of a high enough quality and sufficient meteorological interest to merit further study (e.g., Renfrew 2004). These are, to our knowledge, the first autonomous wintertime soundings of the lower atmosphere over Antarctica. Hence, in the primary sense, the experiment has been a significant success.

In general, the height range of the accurate wind observations was a little disappointing. Following both automatic and visual quality control of the data, pro- files were typically limited to 100-300 m (see Fig. 4) and rarely achieved the $500 \mathrm{~m}$ that we had anticipated based on the manufacturers specifications, and data from a non-Doppler monostatic system that was operated in previous years at Halley Station. The system error values that were reported for poor data indicated that the signal-to-noise ratio was the primary problem. This may be a result of a poor signal (reduced backscatter) or enhanced noise. The following section discusses these twin aspects of poor profile range, referring to a number of unusual aspects of the field site.

Acoustic radars measure echo returns from smallscale atmospheric variations in acoustic refractive index, which are essentially the differences in temperature. A mass of air with a significant spatial variability in temperature at the right length scales will scatter a pulse of sound. A small but measurable fraction of the transmitted pulse is scattered by $180^{\circ}$ and can, therefore, be detected by a monostatic system. A thorough analysis of acoustic scattering, based on the theory of Tatarskii (1971), may be found in, for example, Ottersten et al. (1974) and Beran et al. (1973). The parameters that are relevant to the present discussion are expressed in the normalized echo-strength equation (Beran et al. 1973)

$$
\frac{P_{r}}{P}=\frac{\sigma c \tau}{2} A R^{-2} L
$$




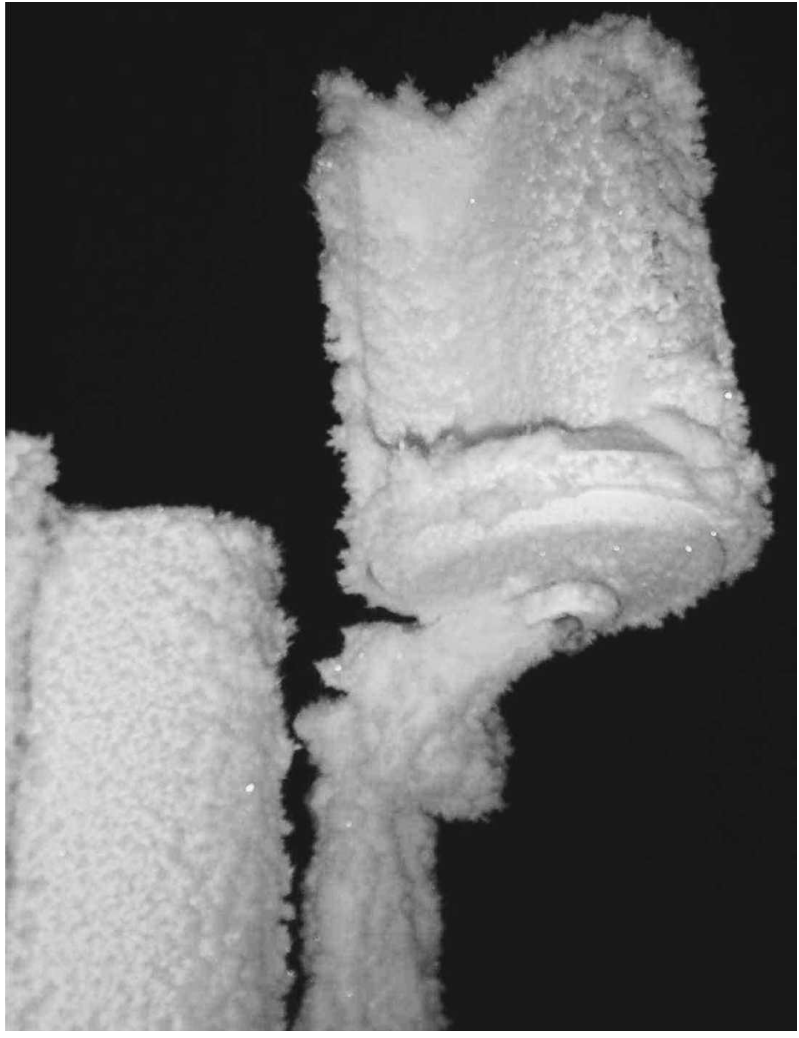

FIG. 9. Rime buildup on the wind generator impeller observed during the wintertime power system tests in 2001.

where $P_{r}$ is the return-echo strength that is normalized by the transmitted power $P ; \sigma$ is the scattering cross section; $c$ is the speed of sound; $\tau$ is the pulse length; $A$ is the antenna area; $R$ is the radial range; and $L$ is a factor containing equipment efficiencies, antenna gain, and atmospheric absorption. Two parameters that may affect the performance of a known sodar operating in a novel environment are the scattering $\sigma$ and the attenuation factor in $L$.

\section{a. Scattering}

The present understanding of the factors that govern acoustic scattering by atmospheric turbulence relies on a number of assumptions regarding the spatial dependence of the bulk temperature variation within the scattering volume (Beran et al. 1973). The bulk temperature variability is quantified as the temperature structure functions $C_{T}^{2}$,

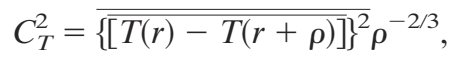

where $T$ is the temperature, $r$ is a position vector, $\rho$ is the separation vector, and $C_{T}^{2}$ is an in situ measurable quantity. Asimakopoulos et al. (1976) show that, in- deed, there is good agreement between $C_{T}^{2}$ and $\sigma$ for a separation vector that is equivalent to half of the acoustic wavelength. Sodar design theory, therefore, depends on using $C_{T}^{2}$ as an estimate for $\sigma$. Deriving estimates of $C_{T}^{2}$ from local conditions, such as temperature gradient and wind shear, is not straightforward for strongly stratified conditions. For instance, the present theory, initially put forward by Tatarskii (1971), assumes homogenous and isotropic turbulence, neither of which is expected under strong stability resulting from turbulent intermittency. In addition, the relation between $C_{T}^{2}$ and $\sigma$ has not been tested under stable conditions. Hence, the quantitative effect on $\sigma$ of increasing atmospheric stratification is unknown.

Field measurements imply that under favorable conditions, a stably stratified atmosphere can generate large values of $C_{T}^{2}$ when a bulk temperature gradient is mixed by shear-driven turbulence. This may happen near the surface, where surface stress generates turbulence within the stratified flow, or aloft, where waves or inertial effects again generate shear turbulence. In the absence of significant shear, that is, for a large Richardson number flow, $C_{T}^{2}$ should be small because of the suppression of mixing, despite the presence of a bulk temperature gradient. Anderson (2003) shows such a case where both measured acoustic backscatter and estimated $C_{T}^{2}$ were negligible, despite local temperature gradients being a maximum and in excess of $0.015 \mathrm{~K}$ $\mathrm{m}^{-1}$. In the absence of temperature profiles at the Doppler sodar site, we are unable to estimate the Richardson number and hence make even a qualitative guess at the expected value of $C_{T}^{2}$. However, we would expect wind shear to tend to small values above the katabatic zone, while thermal gradients could be significant.

\section{b. Attenuation}

Sound is absorbed by the atmosphere. Attenuation is more pronounced at higher frequencies and hence long duration, low-frequency pulses are used to probe the upper boundary layer, while short pulses at higher frequencies are used to profile near the surface. The multifrequency aspects of the FAS64 that is used in this study makes the best of both worlds.

Attenuation is also sensitive to moisture. Crescenti (1998), Simmons et al. (1971), and Neff (1975) report on the expected reduction in attenuation with increasing relative humidity $(\mathrm{RH})$; "wetter" air is better at transmitting sound. This result is for relatively warm air, however, and hides the more complex dependence of acoustic absorption on both humidity and temperature. Figure 10 shows that attenuation is minimal at low temperatures $\left(<-40^{\circ} \mathrm{C}\right)$, and increases slightly with 


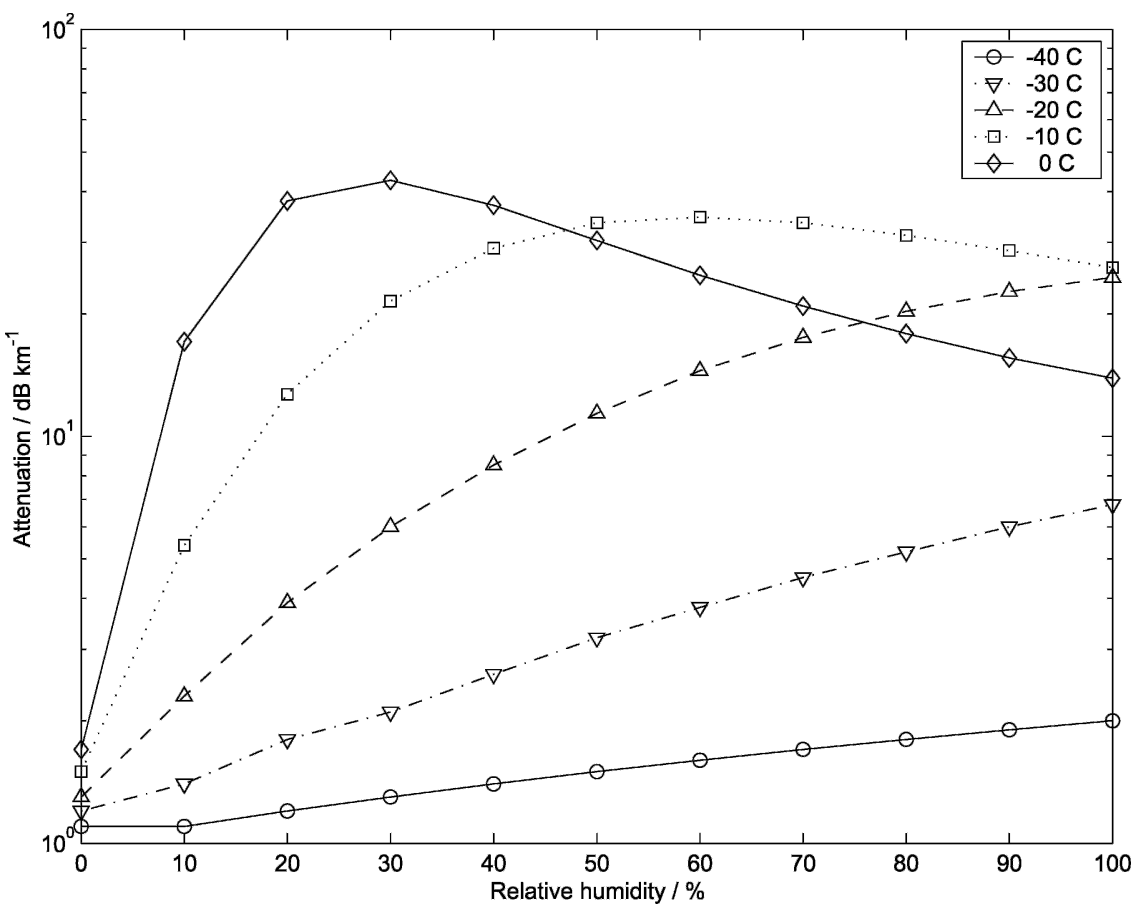

FIG. 10. Attenuation of sound as a function of relative humidity with respect to water $(\mathrm{RH})$ for a number of temperatures. There is a maximum in attenuation at $30 \% \mathrm{RH}$ for moderate temperatures $\left(>0^{\circ} \mathrm{C}\right)$; hence, sodars will work better in humid conditions in midlatitudes. For cooler temperatures, especially $<-20^{\circ} \mathrm{C}$, there is no such maximum. Hence, sodars in polar environments will work better in drier air. Data are taken from ISO 9613 (generating code courtesy of Richard Lord, National Physical Laboratory).

RH. At moderate temperatures $\left(>-20^{\circ} \mathrm{C}\right)$ there is a local maximum in attenuation at around $30 \% \mathrm{RH}$, decreasing for higher values of RH. Overall, the attenuation is greater at warmer temperatures. Data are taken from FASRUN 9613 part 1 tables as provided by the National Physical Laboratory on acoustic attenuation in air. The mechanism for the complex behavior of attenuation with humidity is described in Antoniou et al. (2003); for a more detailed treatment, see Salomons (2001). We conclude, therefore, that in the cooler temperatures of wintertime polar regions, and especially in the dry atmosphere of katabatic flow, attenuation will be weaker than in midlatitudes and hence the expected sodar performance should be improved.

\section{c. Tuning}

The Scintec International Organization for Standardization (ISO) software allows complete user control of all aspects of the multifrequency transmission pulses, such as pulse length, range gate, frequency, and frequency order. Under ideal conditions, this flexibility is essential when operating a sodar under novel conditions to get the best from the system, but a period of tuning and learning is required to understand the system response when changing the many parameters.
We were heavily hampered in tuning the system because of the combination of power limitations (see above), logistical problems in the year of installation (see Turner et al. 2002), and operating the system doubly remotely from the United Kingdom, via overwintering staff at Halley. None of the wintering staff were familiar with Doppler sodars, and they were limited in their remit to run the system for testing; once the total wintertime power was known to be limited, we needed each observation period to gather data, and not just system information. It was soon apparent that the katabatic regime was quite shallow, and the preliminary pulse transmission regimes we had chosen appeared to capture the lower-level winds well.

Multiple-frequency sodars allow for a better overall performance by using short-duration pulses at high frequencies and longer-duration pulses at lower frequencies. The high frequencies are ideal to capture nearsurface detail, but are attenuated very rapidly. Long wavelengths travel farther, but require longer pulses and range gates to ensure that their frequency characteristics are well defined for spectral analysis. The Scintec FASRUN uses all available frequency data to build the resulting wind speed profile, and hence modifying for range may well have a deleterious effect on near- 
surface performance. Tuning is, therefore, difficult under such conditions, and is exacerbated by the day-today atmospheric variability, which confounds attempts to intercompare any given transmission parameter sets. This aspect of tuning makes real-time communication with an autonomous sodar almost a necessity. In addition, a power reserve for continual operation, when conditions allow, will be vital to give enough data for building a parameter table for differing conditions.

\section{d. Baffles and noise}

Phased-array Doppler sodar designs differ from vintage sodar in that older systems are based around a speaker/microphone pointing down onto a parabolic dish. This dish design has a well-defined large primary sidelobe, which must be absorbed in order to define the acoustic beam. The absorber is most usually in the form of a 2-m-high bucket-shaped enclosure, giving these systems a distinctive image. Three antennas are used, with two of them pointing off vertical to measure horizontal Doppler shift, and hence wind profile. Such a system was deemed impractical for autonomous polar use, because of snow accumulation in the buckets.

Phased-array systems are usually sold with small baffles, but their geometry ensures that the acoustic beam has minimal sidelobes. Hence, phased-array systems can work just as well without baffles, so that the baffles are used mostly to reduce the near-field acoustic pattern for users working close to the system, and to eliminate static echoes from nearby buildings. Static echoes can be a problem if a solid structure is face on to the antennas-even though the sidelobes are small, such structures generate a very strong echo, and this un-Dopplered signal can obscure a genuine frequency shift from an atmospheric return.

Because even the small baffle that is offered with the Scintec FAS would have acted as a snow trap, for remote deployment the baffles were removed. This may have had an undesirable effect on the sensitivity of the receiver to wind noise during high wind speeds, but did not appear to affect the performance for lower wind speeds.

Fixed echoes were not the source of data degradation at the field site; such errors would be reported in the quality criteria report for the profile data. The lack of fixed echoes is not surprising because there are no surface features or buildings in any direction. The FAS64 detects, flags, and then filters small fixed echoes, while large fixed echoes generate fatal errors. The cause of low data quality at all wind speeds was predominantly a poor signal-to-noise ratio.

The nearby clutter of AWS masts, photovoltaic arrays, etc., may have caused "ringing," which is the re- transmission of resonant vibration from (typically metal) structures in the vicinity. Ringing is manifest as an apparent continuation of the transmit pulse, and tends to degrade near-surface sodar signals. Ringing invariably decays rapidly in time and is, therefore, unlikely to be a source of degradation of the upper-level signal-to-noise levels. It would also be a near-continual problem for a system, and the range difficulties that we experienced were sporadic.

The benefits of having the baffles removed were that the system appeared to maintain a snow-free antenna; the katabatic regime tends to be dry, and snowfall at the Coats Land Mesoscale Project (CLAMP) site is usually accompanied by strong winds (either katabatic or synoptic). Such wind flow with associated "dry" snow tended to clean the transducer area as effectively as a sand blaster.

We conclude that the relatively poor range performance that we experienced with FAS64 at moderate wind speeds is the result of the stratified state of the upper boundary layer atmosphere at our sounding site, confounded by our inability to suitably tune the system for these conditions. Strongly stable conditions are the norm over Antarctica during winter, leading to a highly stratified flow with minimal turbulence (King and Turner 1997; Anderson 2003). We believe that the stratified nature of the flow reduces the acoustic backscatter and thus the range of the system, especially at heights that are well above the surface layer where the generation of turbulence by wind shear is weakest.

The sodar may have a lower-than-expected wind threshold, that is, the point where wind noise over the array and local masts swamps the return signal. This, in turn, may be the result of the lack of baffles, the mounting of the antenna above the surface, and the smooth nature of the snow.

In our system, the antenna was raised $2 \mathrm{~m}$ above the snow surface on legs (Fig. 2) to avoid being buried by snow accumulation. Unfortunately, this would have increased the wind speed impact on the antenna, compared to a position on the surface. Furthermore, snow is exceptionally smooth in terms of surface roughness, meaning that higher wind speeds are observed near the surface than for equivalent conditions over rougher surfaces, such as grass or forest. Although these constraints were known at the time of deployment, the annual snow accumulation at the Coats Land site left us no obvious alternative to an elevated platform.

A concern prior to the experiment was the possibility that snow would accumulate on the antenna itself, thus, deadening the emitted acoustic pulses and causing a drop in data quality. The antenna does have heating, but this was not used because of power constraints. 
Instead, we extrapolated our experiences with other instruments and structures in Coats Land and assumed that the persistent easterly synoptic and southerly katabatic winds coupled with the smooth, open design of the antenna would allow the (generally) dry and nonaggregating snow to be blown off the antenna, rather than it accumulating on it. We were pleased to find that during testing and remote deployment, this was generally the case.

\section{Summary}

An autonomous Doppler sodar wind profiling system has been designed, built, and then operated at a remote site over a 2-yr period. The system was powered by a modular power system incorporating lead-acid batteries, photovoltaic panels, and vertical axis wind generators. Although the system experienced severe environmental damage during its first year of deployment, in 2002 , it was still able to provide the first wintertime boundary layer wind profiles of Antarctic katabatic flow. The system was controlled in real time by UHF radio telemetry from a controlling $\mathrm{PC}$ located at a manned Antarctic station 45.5-km distant.

During the 2-yr experiment, dozens of sounding periods were obtained, lasting typically $12-48 \mathrm{~h}$. In general, the wind profiles were of a high quality, although their range was often disappointing, a limitation that is thought to be the result of the strongly stable atmospheric conditions that suppress turbulence and hence acoustic backscatter. Moderate-to-high wind speeds posed an environmental noise problem at the antenna and meant that data quality at these times was very poor. However, the same winds kept the antenna free from snow accumulation, thus, allowing for year-round remote sounding.

Acknowledgments. We thank the wintering meteorological observers at Halley from 2000 to 2003: Dan Carson, Liz Hudd, Cathy Moore, Annette Faux, Elaine Cowie, and Stuart Colley. We also thank the employees of Scintec for their help and assistance in determining solutions to the technical problems we have encountered, in particular, Volker Thiermann, Clemens Druee, and Frank Huebner. The manufacturers of the individual components of the autonomous Doppler sodar system described are named for the convenience of the reader. This should not be taken to imply endorsement-either by the authors or by the British Antarctic Survey-of these products, or to exclude the possibility that other products may be equally suitable for the purpose described.

\section{REFERENCES}

Anderson, P. S., 2003: Fine-scale structure observed in a stable atmospheric boundary layer by Sodar and kite-borne tethersonde. Bound.-Layer Meteor., 107, 323-351.

_ S. D. Mobbs, J. C. King, I. McConnell, and J. M. Rees, 1992: A microbarograph for internal gravity wave studies in Antarctica. Antarct. Sci., 4, 241-248.

Antoniou, I., H. E. Jorgensen, F. Ormel, S. Bradley, S. von Hunerbein, S. Emeis, and G. Warmbier, 2003: On the theory of SODAR measurement techniques. Riso National Laboratory Final Report on WP1, EU WISE Project NNE5-2001297, Rep. RISO-R-1410 (EN), 60 pp.

Argentini, S., and G. Mastrantonio, 1994: Barrier winds recorded during two summer Antarctic campaigns and their interaction with the katabatic flows as observed by a tri-axial Doppler sodar. Int. J. Remote Sens., 15, 455-466.

Asimakopoulos, D. N., R. S. Cole, S. J. Caughey, and B. A. Crease, 1976: A quantitative comparison between acoustic sounder returns and the direct measurement of atmospheric temperature fluctuations. Bound.-Layer Meteor., 19, 137-147.

Beran, D. W., W. H. Hooke, and S. F. Clifford, 1973: Acoustic echo-sounding techniques and their application to gravitywave, turbulence and stability studies. Bound.-Layer Meteor., 4, 133-153.

Bromwich, D. H., and Z. Liu, 1996: An observational study of the katabatic wind confluence zone near Siple Coast, West Antarctica. Mon. Wea. Rev., 124, 462-477.

Crescenti, G. H., 1998: The degradation of Doppler sodar performance due to noise: A review. Atmos. Environ., 32, 14991509.

Fiocco, G., G. Mastrantonio, R. Ocone, and S. Argentini, 1990: Acoustic sounder experiments in Victoria Land, Antarctica. Proc. Fifth Int. Symp. on Acoustic Remote Sensing of the Atmosphere and Oceans, New Delhi, India, McGraw Hill, 272-282.

Glickman, T. S., 2000: Glossary of Meteorology. 2d ed. Amer. Meteor. Soc., 855 pp.

Hall, F. F., Jr., and E. J. Owens, 1975: Atmospheric acoustic echo sounding investigations at the South Pole. Antarct. J. U.S., 10, 191-192.

King, J. C., 1993: Control of near-surface winds over an Antarctic ice shelf. J. Geophys. Res., 98, 12 949-12954.

_- and J. Turner, 1997: Antarctic Meteorology and Climatology. Cambridge University Press, 409 pp.

_ S. D. Mobbs, M. S. Darby, and J. M. Rees, 1987: Observations of an internal gravity wave in the lower troposphere at Halley, Antarctica. Bound.-Layer Meteor., 39, 1-13.

Mastrantonio, G., R. Ocone, and G. Fiocco, 1988: Acoustic remote sensing of the Antarctic boundary layer. Proc. First Workshop Italian Research on Antarctic Atmosphere, Bologna, Italy, Italian Physical Society, 137-144.

$-, \ldots,-$, and A. Pellegrini, 1990: Sodar observations of the Antarctic boundary layer in a deglaciated area: Preliminary results. Nuovo Cimento, 13C, 589-597.

Neff, W. D., 1975: Quantitative evaluation of acoustic echoes from the planetary boundary layer. NOAA Tech. Rep. ERL322-WPL 38, $34 \mathrm{pp}$.

_ 1978: Boundary layer research at South Pole Station using acoustic remote sensing. Antarct. J. U.S., 13, 179-181. , 1996: Advances in the remote sensing of the Antarctic boundary layer. Proc. Eighth Int. Symp. on Acoustic Remote Sensing of the Atmosphere and Oceans, Moscow, Russia, A.M. Obukhov Institute of Atmospheric Physics, 61-610. 
— the Atmospheric Boundary Layer, D. H. Lenschow, Ed., Amer. Meteor. Soc., 201-239.

Ottersten, H., M. Hurtig, G. Stilke, B. Brummer, and G. Peters, 1974: Shipbourne sodar measurements during Jonsway 2. J. Geophys. Res., 79, 5573-5584.

Panofsky, H. A., and J. A. Dutton, 1984: Atmospheric Turbulence. Wiley.

Rees, J. M., and S. D. Mobbs, 1988: Studies of internal gravity waves at Halley Base, Antarctica, using wind observations. Quart. J. Roy. Meteor. Soc., 114, 939-966.

Renfrew, I. A., 2004: The dynamics of idealised katabatic flow over a moderate slope and ice shelf. Quart. J. Roy. Meteor. Soc, 130, 1023-1046.

— ordinary katabatic wind regime in Coats Land, Antarctica. Tellus, 54A, 463-484.
Salomons, E. M., 2001: Computational Atmospheric Acoustics. Kluwer Academic, 335 pp.

Simmons, W. R., J. W. Wescott, and F. F. Hall Jr., 1971: Acoustic echo sounding as related to air pollution in urban environments. NOAA Tech. Rep. ERL-216-WPL 17, 77 pp.

Tatarskii, V. I., 1971: The Effects of the Turbulent Atmosphere on Wave Propagation. Israel Program for Scientific Translations, 472 pp.

Turner, J., S. A. Harangozo, G. J. Marshall, J. C. King, and S. R. Colwell, 2002: Anomalous atmospheric circulation over the Weddell Sea, Antarctica during the austral summer of 2001/ 02 resulting in extreme sea ice conditions. Geophys. Res. Lett., 29, 2160, doi:10.1029/2002GL015565.

Ye, Y., X. Cai, J. C. King, and I. A. Renfrew, 2005: Numerical simulations of katabatic jumps in Coats Land, Antarctica. Bound.-Layer Meteor., 114, 413-437. 